\title{
Organic versus conventional tomatoes: Influence on physicochemical parameters, bioactive compounds and sensorial attributes
}

\author{
Ana F. Vinha, Sérgio V.P. Barreira, Anabela S.G. Costa, Rita C. Alves,M. Beatriz P.P. Oliveira
}

\begin{abstract}

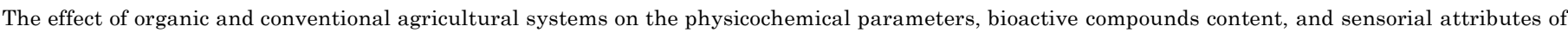

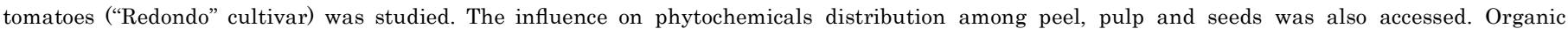

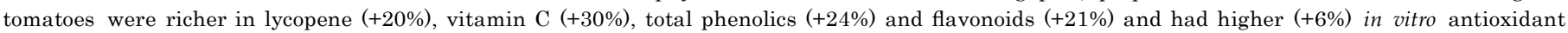

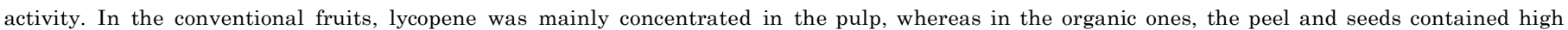

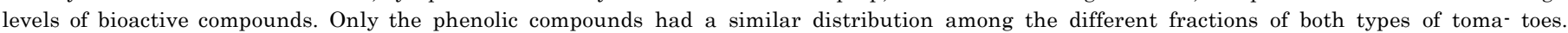
Furthermore, a sensorial analysis indicated that organic farming improved the gustative properties of this tomato cultivar.
\end{abstract}

Keywords:

Organic tomatoes, Antioxidant activity, Phytochemicals, Sensory attributes

\section{Introduction}

In the last century, new agricultural technologies and the massive use of chemical fertilizers, pesticides and herbicides provided an increased productivity at lower prices. The abuse of such substances resulted in pollution and ecosystems imbalance, and sev- $^{-}$ eral studies reported a causal relationship between their use and the increase of cancers and congenital disorders in humans (Gold et al., 2001; Sanborn et al., 2007).

In the last two decades, organic agriculture has been increasing in order to meet the demand of a growing number of consumers who are willing to pay more for food produced by environmentally friendly practices and without pesticide residues (Didier and Lucie, 2008). One question remains without a clear answer, however, and that is whether the organic management system really improves or not the nutritional and organoleptic characteristics of the products.

Several studies have pointed out a better quality of organic foods compared to those from conventional production. For example, in a meta-analysis that included 41 studies, Worthington (2001) concluded that organic products have higher vitamin C, iron, magnesium, and phosphorus contents and lower nitrate values. Magkos et al. (2001) reviewed that organically grown leafy vegetables and potatoes have higher levels of vitamin C. In addition, higher phytochemical content and total antioxidant activity was observed in organic oranges (Tarozzi et al., 2006) and higher levels of phenolic compounds were found in organic apples (Petkovsek et al., 2010) compared to the counterparts produced in integrated systems. In a comparative study carried out with two types of tomato (standard and cherry), Hallmann (2012) also found that organic fruits contained higher contents of total sugars, vitamin $\mathrm{C}$ and total flavonoids. In turn, Cwalina-Ambroziak and Amarowicz (2012) stated that the use of biological and fungicidal control agents was negatively correlated with the levels of carotenoids and phenolic compounds in tomato fruits.

Nevertheless, the scientific opinion is far from being consensual, since several studies claim that there is no differences between the nutritional quality of organically and conventionally produced foodstuffs. For instance, Cardoso et al. (2011) concluded that there was no evidence of nutritional superiority of organically grown fruits (acerola, strawberries and persimmon) regarding vitamin C and carotenoids contents. Also, Gravel et al. (2010) found little differences in what concerns to taste and nutritional value of organic and conventionally grown tomatoes in greenhouses.

There is no question that the consumption of organic foods may reduce exposure to pesticide residues and antibiotic-resistant bacteria (Smith-Spangler et al., 2012), but given the number of contradictory results about the possible nutritional benefits, new data 
from controlled paired studies is essential to reach more conclusive results.

In this work, we sought to evaluate the effect of the cropping system (organic and conventional) on quality parameters (physicochemical properties, contents of bioactive compounds, antioxidant activity and organoleptic properties) of a Portuguese tomato cultivar ("Redondo"), which at present is produced almost exclusively by conventional means. As this tomato variety is widely appreciated by both home kitchen and industry of tomato-based products, the distribution of the nutrients among peel, pulp and seeds was also accessed.

\section{Materials and methods}

\subsection{Chemicals and reagents}

2,6-Dichloroindophenol sodium salt hydrate, meta-phosphoric acid, gallic acid, catechin, Folin-Ciocalteu's phenol reagent, DPPH (2,2-diphenyl-1-picrylhydrazyl radical), sodium nitrite, aluminium chloride, $\mathrm{n}$-hexane, methanol, and acetone were all obtained from Sigma-Aldrich (St. Louis, USA). Anhydrous sodium carbonate, sodium hydroxide and absolute ethanol were purchased from Merck (Darmstadt, Germany). Ultrapure water was treated in a Milli-Q water purification system (Millipore, Bedford, MA, USA) and used to prepare all aqueous solutions.

\subsection{Samples and sample preparation}

Sane and mature tomato fruits (Lycopersicon esculentum L.) from "Redondo" cultivar were harvested from two nearby greenhouses located in the littoral North of Portugal, Póvoa de Varzim (Latitude: 41.3826, Longitude: $-8.7627941^{\circ} 22^{0} 57^{\mathrm{W}}$ North, $8^{\circ} 45^{0} 46^{10}$ West) on September 2012. The cropping differences between the two greenhouses were only related with pest control and soil fertilization. According to the producer, in the conventional production, a synthetic fertilizer (Diamant $\left.{ }^{\circledR}\right)$ was applied every week, while in organic production an organic fertilizer NPK (Agrimartin ${ }^{\circledR}$ ) was incorporated into the soil, just before sowing. In the greenhouse used for conventional production, downy mildew and rottenness were prevented by spraying the plants every 15 days with a fungicide whose active ingredient is Folpet and with Rovral ${ }^{\circledR}$. In the organic greenhouse, the producer used a $0.5 \%$ Bordeaux mixture (copper sulfate + slaked lime) as preventive fungicide. To control tomato caterpillars (Helicoverpa armigera) in the conventional cultivation system, the plants were sprayed with the insecticide KarateZeon ${ }^{\circledR}$ every 15 days. In the organic greenhouse, spinosad was used instead. Tuta absoluta was controlled in both greenhouses by means of pheromone traps.

The producer reported that the conventional production reached on average $1 \mathrm{t} \mathrm{ha}^{-1}$, and "' $10 \%$ of these fruits were rejected due to defects. The amount of tomatoes produced in the organic greenhouse reached "' $0.55 \mathrm{t} \mathrm{ha}^{-1}$ and $20 \%$ were lost due to defects.

One hundred tomatoes were randomly harvested from each of the greenhouses (no more than three fruits per tomato plant) and immediately refrigerated at $4{ }^{\circ} \mathrm{C}$. Six independent samples were analyzed for each type of treatment: whole fruits, fruits without peel and fruits without seeds. Each independent sample was prepared by homogenizing (MX-291-N, National, Osaka, Japan) four freshly collected washed fruits (whole, peeled or without seeds). Samples were then transferred into an amber air-tight container, flushed with nitrogen, and stored at $-20^{\circ} \mathrm{C}$. All analyses were performed within two weeks after sample preparation.

\subsection{Physicochemical analysis}

Moisture was determined by drying $5.0 \mathrm{~g}$ of sample at $105 \pm 1^{\circ} \mathrm{C}$, until constant weight (AOAC, 2000). Results were expressed in water percentage. The water activity $\left(a_{\mathrm{w}}\right)$ was measured using a Rotronic Hygropalm 9 VCD (Rotronic Instruments Ltd., Crawley, UK). A pH-meter (Microprocessor pH Bench-top HI 8417, Hanna Instruments) was used to determine $\mathrm{pH}$ values. Total soluble solids (TSS), expressed as ${ }^{\circ}$ Brix, were determined using a NAR-3T refractometer (Atago Co. Ltd., Tokyo, Japan), adjusted and calibrated at $20^{\circ} \mathrm{C}$ with distilled water. Color readings were performed with a Color Quest II Sphere colorimeter (Hunter Lab, Reston, VA). The $a^{*}$ (red-green) and $b^{*}$ (yellow-blue) values were used to calculate the hue angle value, $\mathrm{h}^{\circ}=\tan ^{-1}\left(b^{*} / a^{*}\right)$. Analyses were performed in triplicate. Results are presented in Table 1.

\subsection{Phytochemicals analysis}

\subsubsection{Ascorbic acid}

Ascorbic acid content was determined, in triplicate, according to Vinha et al. (2014). Very briefly, sample aliquots were mixed with meta-phosphoric acid $(0.1 \mathrm{~g} / \mathrm{L})$ for $45 \mathrm{~min}$ at room temperature and filtered. A filtrate aliquot was mixed
Table 1

Physicochemical parameters of the tomato fruits obtained from two agricultural management systems (conventional and organic).

\begin{tabular}{|c|c|c|c|}
\hline Parameter & Fraction & Conventional & Organic \\
\hline \multirow[t]{3}{*}{ Moisture (\%) } & Whole & $91.1 \pm 0.2^{\mathrm{b}}$ & $91.1 \pm 0.4^{\mathrm{a}}$ \\
\hline & Without peel & $92.4 \pm 0.5^{\mathrm{a}}$ & $91.9 \pm 0.9^{\mathrm{a}}$ \\
\hline & $\begin{array}{l}\text { Without } \\
\text { seeds }\end{array}$ & $91.0 \pm 0.1^{\mathrm{b}}$ & $91.4 \pm 0.1^{2 /}$ \\
\hline \multirow[t]{3}{*}{ Water activity } & Whole & $0.96 \pm 0.01^{\mathrm{a}}$ & $0.96 \pm 0.01^{\mathrm{a}}$ \\
\hline & Without peel & $0.96 \pm 0.01^{\mathrm{a}}$ & $0.96 \pm 0.01^{\mathrm{a}}$ \\
\hline & $\begin{array}{l}\text { Without } \\
\text { seeds }\end{array}$ & $0.96 \pm 0.01^{\mathrm{a}}$ & $0.96 \pm 0.01^{\mathrm{a}}$ \\
\hline \multirow[t]{3}{*}{ Acidity (pH) } & Whole & $4.46 \pm 0.04^{\mathrm{b}}$ & $4.38 \pm 0.01^{\circ}$ \\
\hline & Without peel & $4.51 \pm 0.01^{\mathrm{a}}$ & $4.56 \pm 0.01^{2}$ \\
\hline & $\begin{array}{l}\text { Without } \\
\text { seeds }\end{array}$ & $4.51 \pm 0.01^{\mathrm{a}}$ & $4.43 \pm 0.01^{b}$ \\
\hline \multirow{3}{*}{$\begin{array}{l}\text { Total soluble solids (TSS) } \\
\quad\left({ }^{\circ} \text { Brix }\right)\end{array}$} & Whole & $3.21 \pm 0.01^{\mathrm{c}}$ & $3.90 \pm 0.01^{2-}$ \\
\hline & Without peel & $3.29 \pm 0.01^{\mathrm{b}}$ & $3.89 \pm 0.01^{2-}$ \\
\hline & $\begin{array}{l}\text { Without } \\
\text { seeds }\end{array}$ & $3.36 \pm 0.01^{\mathrm{a}}$ & $3.40 \pm 0.01^{\mathrm{b}}$ \\
\hline \multirow[t]{3}{*}{ Hue angle $\left({ }^{\circ} \mathrm{h}\right)$} & Whole & $67.1 \pm 3.9^{\mathrm{a}}$ & $46.8 \pm 0.7^{\mathrm{b}}$ \\
\hline & Without peel & $70.2 \pm 1.8^{\mathrm{a}}$ & $53.4 \pm 1.4^{2-}$ \\
\hline & $\begin{array}{l}\text { Without } \\
\text { seeds }\end{array}$ & $53.5 \pm 1.7^{\mathrm{b}}$ & $38.5 \pm 0.5^{c}$ \\
\hline
\end{tabular}

Results expressed as mean \pm standard deviation obtained from triplicate measure ments of six independent samples. Within each column, and for each individual parameter, different letters indicate significant differences $(p<0.05)$ between tomato fractions. The symbol " was used to indicate that the value of a parameter for a fraction of organic fruits is statistically different $(p<0.05)$ from that of the corresponding fraction on conventionally produced fruits.

with 2,6-dichloroindophenol, and spectrophotometric measurements were performed at $515 \mathrm{~nm}$. Analyses were performed in triplicate and results were expressed as milligrams of ascorbic acid per $100 \mathrm{~g}$ of sample.

\subsubsection{Total phenolics}

Total phenolics were determined, in triplicate, according to Vinha et al. (2014) Briefly, "' $5 \mathrm{~g}$ of sample were extracted with $100 \mathrm{ml}$ of methanol/water $(80 / 20 \mathrm{v} / \mathrm{v})$ for $1 \mathrm{~h}$. After that, $5001 \mathrm{~L}$ of Folin-Ciocalteu reagent (1:10) were added to a filtrate aliquot $(2 \mathrm{ml})$. The mixture was left $3 \mathrm{~min}$ at $25^{\circ} \mathrm{C}$ before $0.2 \mathrm{ml}$ of a saturated sodium carbonate solution being added. After standing at room temperature, absorbance readings were performed at $725 \mathrm{~nm}$. Gallic acid was used as calibration standard.

As ascorbic acid also reacts with the Folin-Ciocalteu reagent, total phenolic contents were corrected for the ascorbic acid interference, according to Asami et al. (2003). The same methodology used for total phenolics quantification was performed for ascorbic acid standards and a calibration curve was obtained. The concentrations of ascorbic acid measured spectrophotometrically as described in Section 2.4.1 were then used to evaluate the contribution of the ascorbic acid to the absorbance detected in the total phenolics assay. Results were expressed as $\mathrm{mg}$ of gallic acid equivalents (GAE) per $100 \mathrm{~g}$ of sample.

\subsubsection{Total flavonoids}

Total flavonoids were estimated according to Alothman et al. (2009). Briefly, sample extracts $(1 \mathrm{ml})$ were mixed with deionized water $(4 \mathrm{ml})$ and $3 \mathrm{ml}$ of $\mathrm{NaNO}_{2}$ $(5 \% \mathrm{w} / \mathrm{v})$. The mixture was left to stand for $5 \mathrm{~min}$ before $0.3 \mathrm{ml}$ of $\mathrm{AlCl}_{3}(10 \%)$ were added, followed by $2 \mathrm{ml}$ of $1.0 \mathrm{M} \mathrm{NaOH}$ after one more minute. The volume was completed to $10 \mathrm{ml}$ with distilled water. The reaction mixture was mixed thor oughly for homogenization and absorbance was measured at $510 \mathrm{~nm}$. Analyses were performed in triplicate. Catechin was used as calibration standard and results were expressed as mg of catechin equivalents (CE) per $100 \mathrm{~g}$ of sample.

\subsubsection{Lycopene}

Lycopene content was determined, in triplicate, according to Alda et al. (2009) with few modifications. Approximately $5 \mathrm{~g}$ of sample were added to a $50 \mathrm{ml} \mathrm{mix}$ ture of hexane/acetone/ethanol $(2: 1: 1, \mathrm{v} / \mathrm{v} / \mathrm{v})$ and incubated at ambient temperature $\left(21^{\circ} \mathrm{C}\right)$ for $30 \mathrm{~min}$. The supernatant (hexane layer) absorbance was measured at $472 \mathrm{~nm}$. Absolute hexane was used as blank. The amount of lycopene was estimated using the equation:

\section{Lycopene $\delta \lg =\mathrm{gp} 1 / 4 \delta A \times v \times 10^{6} \mathrm{p}=\varnothing 3450 \times W \times 100 \mathrm{P}$}

where $v$ is the amount of hexane $(\mathrm{ml}), W$ the weight of sample $(\mathrm{g}), A$ the absorbance at $472 \mathrm{~nm}$ and 3450 the molar extinction coefficient. 


\subsection{Antioxidant activity}

The DPPH scavenging capacity of the samples was assessed according to Vinha et al. (2014) with minor modifications. Briefly, $1.5 \mathrm{ml}$ of a fresh DPPH methanolic solution $\left(6 \times 10^{-5} \mathrm{~mol} / \mathrm{L}\right)$ were added to $0.5 \mathrm{ml}$ of a sample extract. The mixture was shaken vigorously and absorbance readings at $515 \mathrm{~nm}$ were performed when a stable plateau was reached. Radical scavenging activity (RSA) was expressed as percentage of DPPH inhibition and calculated through the equation:

$\% \mathrm{RSA} 1 / 4 \mathrm{\partial} A_{\text {control }}-A_{\text {sample }} \mathrm{P}=A_{\text {control }} \times 100$

\subsection{Sensory analysis}

A taste panel consisting on fifty untrained panelists was used. The recruitment criteria included: panelists with ages between 18 and 50 years old; not allergic to tomatoes; able to pass a flavor acuity test; regular consumers of fresh tomatoes (at least once per week); not smokers, and available and willing to participate during testing sessions. Four samples were evaluated in each session (two sessions in total). The panelists were allowed to taste, and evaluate color and aroma of the samples using a 1-7 structured scale (1: dislike completely, 2: dislike, 3: dislike slightly, 4: accept, 5: like slightly, 6 : like, 7 : like very much) according to Villanueva (2003). The final mean score was calculated.

\subsection{Statistical analysis}

A completely randomized design was used with three replications. Statistical analysis was performed using SPSS v. 21 (IBM Corp., Armonk, NY, USA). Data of all analyses w ere expressed as mean \pm standard deviation. Variance analysis was used to compare different fractions of the same type of tomato relatively to each parameter experimentally measured. Tukey's test was employed for multiple comparisons. Mean comparison between conventional and organic fruits was made through independent samples $t$-test. Pearson correlation tests were used to ascertain the existence of linear relationships between the contents of bioactive com pounds and antioxidant activity. The chi-square statistic was used to compare the results of the sensorial analysis of both kinds of tomato. $P$-values inferior to 0.05 were considered to be statistically significant.

\section{Results and discussion}

\subsection{Physicochemical parameters}

The physicochemical parameters of organically and conventionally produced tomatoes are presented in Table 1: moisture (which influences texture, taste and appearance), water activity (a "free water" measure, and an important variable in assessing the propensity for spoilage due to bacterial, mold or yeast contamination), $\mathrm{pH}$ (that influences the fruit flavor, shelf life, and is used as a reliable indicator of its overall quality), total soluble solids (that are related to total sugars and, therefore, determine sensory attributes, particularly taste, sweetness and acidity), and the hue angle $\left({ }^{\circ} \mathrm{h}\right)$, a parameter that is related with the amount of pigments in the fruit, namelylycopene.

Significant differences were observed between both tomato types, except for moisture and water activity. The organic samples presented lower hue angles (which indicates more red color), and a slightly lower $\mathrm{pH}$, but higher TSS. For each kind of tomato, removing the peel had no effect on moisture percentage and water activity. On the contrary, it increased $\mathrm{pH}$ in $1 \%$ and $4 \%$, and the hue angle in $4.7 \%$ and $14 \%$, of conventional and organic fruits, respectively. These observations may be attributed to the fact that the tomato peel is rich in pigments, namely, carotenoids. The $\mathrm{pH}$ increase, particularly in the case of organic tomatoes, may be related to the higher concentration of organic acids (mainly citric and malic) in its pulp fraction.

TSS also increased $2.5 \%$ with peeling of conventional tomatoes, while no changes were observed in organic ones. Removing the seeds also affected differently the levels of TSS of both types of tomatoes, causing a reduction of "' $13 \%$ in the organic fruits and an increase of $5 \%$ in the conventional ones. This leads to infer that seeds may have a negligible contribution to the sugars and acid levels in conventional farming fruits, succeeding the opposite in the case of those produced organically. The hue angle decreased significantly (20.3\% and $17.8 \%$, respectively) when the seeds were removed from fruits, which is certainly related with the fact that the tomato seeds are yellowish. When the corresponding fractions of the two kinds of tomatoes were compared, the major differences were noticed for the all fruit, for all parameters. The organically grown fruits presented $17.7 \%$ more TSS and $30.2 \%$ less hue angle. Overall, these data suggest that the organic farming fruits present a larger amount of pigments and free sugars. The results of trimming also show that the distribution of these components was not identical in the two kinds of tomato. The sugars and acids were concentrated in the pulp in the case of conventional tomatoes, and despite no direct measurements were performed in the seeds, the results appear to indicate that those of the organic fruits also contributed significantly to its sugar and acids contents. The peel of the organic tomatoes seemed to be richer in pigments than that of the conventional fruits.

\subsection{Bioactive compounds contents}

The main reason why tomatoes ingestion is so recommended by health professionals is their high level of antioxidants, namely phenolics, vitamin $\mathrm{C}$ and, in particular, lycopene. These compounds have been associated with several health benefits encompassing the ability to protect the body against cancer (Bhuvaneswari and Nagini, 2005), reducing inflammation (Palozza et al., 2010), and decreasing the amount of LDL cholesterol in the bloodstream (Ried and Fakler, 2011). Table 2 summarizes the influence of the farming method in the contents of all of these phytonutrients for the various fractions of the tomatoes.

The results show that the fruits obtained by organic farming are considerably richer in all the compounds analysed: $+30 \%$ of ascorbic acid, $+20 \%$ of lycopene, $+24 \%$ of total phenolics, and $+21 \%$ of flavonoids. These results agree with the latest findings of Oliveira et al. (2013) who reported that organic tomatoes accumulate higher concentrations of vitamin $\mathrm{C}(+55 \%)$ and phenolic compounds $(+139 \%)$ than those grown on conventional farms. They suggested that the increased stress to which plants are exposed in organic farming may be the reason why organic tomatoes had higher levels of these compounds. In another previous study, Mitchell et al. (2007) had already reported that organically grown tomatoes contained higher levels of some flavonoids (quercetin and kaempferol aglycones) than conventionalones.

The results presented in Table 2 also revealed that, both types of tomato lost bioactive compounds when peel and seeds were removed. The losses caused by peeling were about $11 \%$ and $4 \%$ for ascorbic acid, in conventional and organic fruits, respectively; $1 \%$ and $15 \%$, for lycopene; $10 \%$ and $11 \%$, for total phenolics; and $30 \%$ and $19 \%$, for flavonoids. When seeds were removed, decreases in total phenolics (25\% and $14 \%$ ) and flavonoids (36\% and $38 \%$ ) were

observed, respectively, for conventional and organic tomatoes. A reduction of ascorbic acid content (38\%) and lycopene (16\%) was

also observed in organic fruits, but a slight increase (per $100 \mathrm{~g}$ of sample) of these parameters, not statistically significant in the case

of ascorbic acid, was observed in conventional seedless tomatoes.

These results are consistent with the fact that the tomato fruit epidermis and the seeds are rich in phenolic compounds, lycopene and ascorbic acid, as previously reported by Toor and Savage (2005) for fruits from Excell, Tradiro and Flavourine cultivars.

Peeling accentuated the differences between conventional and organic tomatoes, regarding the contents of ascorbic acid, total phenolics and flavonoids, and the fraction without seeds of the conventional fruits contained more $13 \%$ ascorbic acid than the corresponding organic tomato fraction. The results presented in Table 2 also show that the agricultural method influences not only the contents but also the distribution of the bioactive compounds 

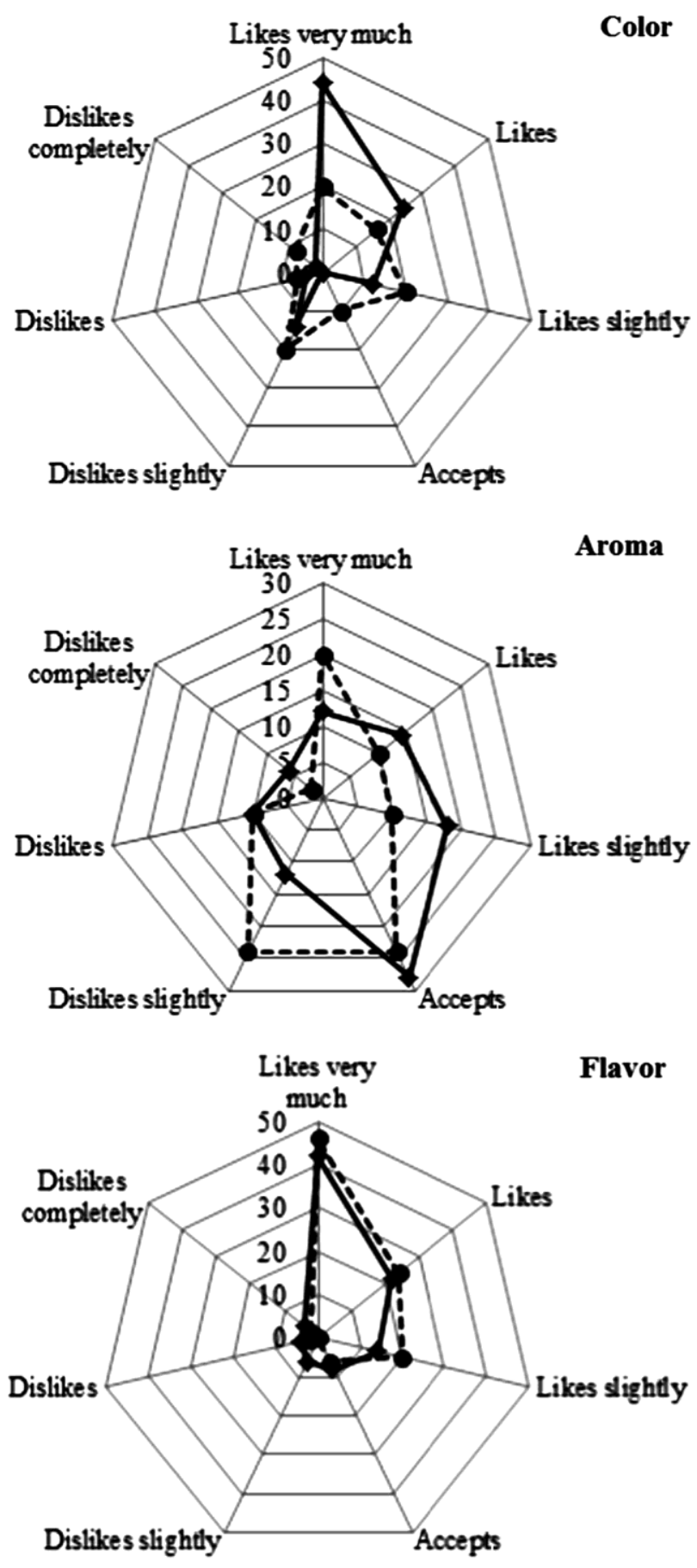

$\longrightarrow$ Conventional $\rightarrow--$ Organic

Fig. 1. Comparative sensorial analysis of "Redondo" tomatoes produced conventionally and organically. Scores are presented as percentages (\%).

in the fruit. The seeds of the organic fruits contained higher levels of ascorbic acid than those of conventionally produced tomatoes. Lycopene was more concentrated on the peel of organic fruits when compared to conventional ones. Only the distribution of phenolic compounds was similar in both tomato categories. These differences in phytochemicals distribution may also be endorsed to the nutrient and insect pest stress to which organically grown tomato plants are subjected. In fact, plant physiological studies indicate that in response to biotic and abiotic stress plants change the composition of their fruit seeds and peel, as part of their defense mechanism (Pérez-Clemente et al., 2013).

\subsection{Antioxidant activity}

The molecules listed in the previous section, and others like bcarotene and vitamin $\mathrm{E}$ that were not quantified in this study, have the ability to inhibit or retard oxidation processes which are, for example, associated with human aging and development of pathologies such as metabolic syndrome, cancer or degenerative disorders (Hamid et al., 2010). Nevertheless, there is some concern that in addition to the inevitable pesticide residues, the antioxidant capacity of foods grown using conventional production systems can be lower than desirable for human health.

In this work, the samples capacity to scavenge the 2,2-diphenyl1-picrylhydrazyl radical (DPPH) was ascertained. Consistent to the fact that organic tomatoes contained higher levels of lycopene, vitamin $\mathrm{C}$ and phenolic compounds (Table 2), it was observed that they also exhibited higher, and statistically different, values of in vitro antioxidant activity (Table 3 ). Positive correlations were found between the antioxidant activity and the contents of all bioactive compounds but they were only significant for total phenolics $(r=0.76)$ and flavonoids $(r=0.89)$ contents.

Both kinds of tomato lost antioxidant capacity when their peel and seeds were removed, since those trimming procedures, as previously discussed, result in loss of lycopene, ascorbic acid and phenolics.

\subsection{Sensorial analysis}

Sensorial analysis is routinely used in industry to discover details on flavor, texture, aroma and color of the products. Although with some subjectivity, these attributes will influence the consumer's preference. In fact, consumers tend to favor mainly sensory characteristics of the products, in particular, appearance, texture, aroma and flavor. It is, therefore, important to assess the extent to which the agricultural system influenced the sensorial characteristics of the "Redondo" tomato from consumers' point of view. To this intent, a sensory panel evaluation of three attributes (color, aroma and flavor) was conducted.

The conventional tomatoes were preferred in terms of color (44\% "liked very much", $24 \%$ "liked" and 12\% "liked slightly", compared to $20 \%, 16 \%$, and $20 \%$ scores of the organic fruit) (see Fig. 1). This result is somewhat surprising, since the hue angle measurements, as well as the lycopene contents, indicated that the organic tomatoes were more pigmented. So, we do not exclude the possibility that some of the panel members, since this is an untrained panel, confused color with appearance. Regarding aroma, the organic fruit had similar percentages of panelists appointing it as preferred and as slightly disliked, a result that demonstrates the subjective nature of consumer's preferences. In a recent study, Vallverdú-Queralt et al. (2013) reported that juices obtained from Spanish and Italian conventional tomato cultivars had lower amounts of volatile compounds than organic ones. The last were, in addition, more diverse in olfactory properties, although they exhibited desirable and undesirable compounds which may explain why their aroma was not so appreciated by some consumers.

It is only with regard to flavor that the organic tomatoes were better evaluated than their conventional counterparts: $46 \%$ "liked very much", $24 \%$ "liked" and 20\% "liked slightly" compared to $42 \%, 22 \%$, and $14 \%$ scores, respectively. This agrees with general findings that organically grown crops have better flavor than those produced conventionally (Weibel et al., 2000). Since most studies continue to point out the appearance/color as the decisive attribute in the moment of purchase (Stommel et al., 2005), based on these 
Table 2

Phytochemicals content of the analyzed tomatoes from different agricultural management systems.

\begin{tabular}{llll}
\hline Phytochemicals & Fraction & Conventional & Organic \\
\hline Ascorbic acid $(\mathrm{mg} / 100 \mathrm{~g})$ & Whole & $27.9 \pm 3.5^{\mathrm{a}}$ & $40.0 \pm 0.8^{2}$ \\
& Without peel & $24.7 \pm 0.8^{\mathrm{a}}$ & $38.4 \pm 1.6^{\mathrm{a}}$ \\
& Without seeds & $28.7 \pm 1.5^{\mathrm{a}}$ & $25.0 \pm 0.8^{\mathrm{b}}$ \\
& Whole & $1.76 \pm 0.13^{\mathrm{b}}$ & $2.19 \pm 0.02^{2}$ \\
Lycopene $(\mathrm{mg} / 100 \mathrm{~g})$ & Without peel & $1.74 \pm 0.10^{\mathrm{b}}$ & $1.87 \pm 0.14^{\mathrm{b}}$ \\
& Without seeds & $1.91 \pm 0.05^{\mathrm{a}}$ & $1.85 \pm 0.11^{\mathrm{b}}$ \\
& Whole & $149 \pm 4^{\mathrm{a}}$ & $196 \pm 1^{2}$ \\
Total phenolics & Without peel & $134 \pm 5^{\mathrm{b}}$ & $175 \pm 8^{\mathrm{b}}$ \\
(mg GAE/100 g) & Without seeds & $111 \pm 4^{\mathrm{c}}$ & $168 \pm 2^{\mathrm{c}}$ \\
& Whole & $40.4 \pm 0.6^{\mathrm{a}}$ & $51.4 \pm 0.9^{2}$ \\
Flavonoids $(\mathrm{mg} \mathrm{CE} / 100 \mathrm{~g})$ & Without peel & $28.1 \pm 0.2^{\mathrm{b}}$ & $41.6 \pm 0.6^{\mathrm{b}}$ \\
& Without seeds & $25.8 \pm 0.6^{\mathrm{c}}$ & $31.8 \pm 0.9^{\circ}$ \\
& &
\end{tabular}

Results expressed as mean \pm standard deviation obtained from triplicate measurements of six independent samples. GAE, gallic acid equivalents; CE, catechin equivalents.

Within each column, and for each individual parameter, different letters indicate significant differences $(p<0.05)$ between tomato fractions. The symbol " was used to indicate that the value of a parameter for a fraction of organic fruits is statistically different $(p<0.05)$ from that of the corresponding fraction on conventionally produced fruits.

Table 3

Antiradical activity of sample extracts (obtained from whole, peeled and seedless tomatoes produced by both conventional and organic practices) against DPPH reported as scavenging percentage (\%)

\begin{tabular}{lll}
\hline Fraction & Conventional & Organic \\
\hline Whole & $58.4 \pm 0.7^{\mathrm{a}}$ & $62.1 \pm 1.3^{\mathrm{a}}$ \\
Without peel & $37.9 \pm 1.9^{\mathrm{b}}$ & $46.1 \pm 0.7^{\mathrm{b}}$ \\
Without seeds & $36.1 \pm 1.8^{\mathrm{b}}$ & $47.9 \pm 0.3^{\mathrm{b}}$ \\
\hline
\end{tabular}

Results expressed as mean \pm standard deviation obtained from triplicate measure ments of six independent samples. Within each column, and for each individual parameter, different letters indicate significant differences $(p<0.05)$ between tomato fractions. The symbol " was used to indicate that the value of a parameter for a fraction of organic fruits is statistically different $(p<0.05)$ from that of the corresponding fraction on conventionally produced fruits.

results, it is expected that in the absence of more information, namely nutritional, conventional tomatoes would be preferred, especially if we add the fact that the organic fruits are usually more expensive.

\section{Conclusions}

The results of this study showed that, in a nutritional perspective, the organic tomatoes analyzed were healthier than those produced by conventional practices, presenting higher phytochemical contents and antioxidant activity. The agricultural system also influenced the nutrients distribution by the different parts of the fruits. The results of the sensory panel evaluation indicated that the highest pigmentation of the organic tomatoes does not guarantee the consumers' preference. The organoleptic attribute at which organic fruits definitely scored better than conventional ones was flavor.

\section{Conflict of Interest}

The authors declare that there are no conflicts of interest.

\section{Transparency Document}

The Transparency document associated with this article can be found in the online version.

\section{Acknowledgments}

R.C. Alves is grateful to FCT for a post-doctoral Grant (SFRH/ BPD/68883/2010) financed by POPH-QREN-Tipologia 4.1-Formação Avançada, subsidized by FSE and MCTES. This work has

been supported by FCT through Grant no. PEst-C/EQB/LA0006/ 2013 and QREN (NORTE-07-0124-FEDER-000069-CIÊNCIA DO ALIMENTO).

\section{References}

Alda, L.M., Gogoasa“, I., Bordean, D.M., Gergen, I., Alda, S., Moldovan, C., Niotǎ,L., 2009. Lycopene content of tomatoes and tomato products. J. Agroalimentary Processes Technol. 15, 540-542.

Alothman, M., Bhat, R., Karim, A., 2009. Antioxidant capacity and phenolic content of selected tropical fruits from Malaysia, extracted with different solvents. Food Chem. 115, 785-788.

AOAC (Association of Official Analytical Chemists), 2000. Official Methods of Analysis, 17th ed. Washington, DC, USA.

Asami, D.K., Hong, Y.J., Barrett, D.M., Mitchell, A.E., 2003. Comparison of the total phenolic and ascorbic acid content of freeze-dried and air-dried marionberry, strawberry, and corn grown using conventional, organic, and sustainable agricultural practices. J. Agric. Food Chem. 51, 1237-1241.

Bhuvaneswari, V., Nagini, S., 2005. Lycopene: a review of its potential as an anticancer agent. Curr. Med. Chem.-Anti-Cancer Agents 5, 627-635.

Cardoso, P., Tomazini, A., Stringheta, P., Ribeiro, S., Pinheiro-Sant'Ana, H., 2011. Vitamin $\mathrm{C}$ and carotenoids in organic and conventional fruits grown in Brazil. Food Chem. 126, 411-416.

Cwalina-Ambroziak, B., Amarowicz, R., 2012. Effects of biological and fungicidal environmental protection on chemical composition of tomato and red pepper fruits. Pol. J. Environ. Stud. 21, 831-836.

Didier, T., Lucie, S., 2008. Measuring consumer's willingness to pay for organic and fair trade products. Int. J. Consum. Stud. 32, 479-490.

Gold, L.S., Slone, T.H., Ames, B.N., Manley, N.B., 2001. Pesticide residues in food and cancer risk: a critical analysis. In: Krieger, R. (Ed.), Handbook of Pesticide Toxicology. Academic Press, San Diego, CA, pp. 799-843.

Gravel, V., Blok, W., Hallmann, E., Carmona-Torres, C., Wang, H., Van De Peppel, A. Golec, A.F.C., Dorais, M., Meeteren, U.V., Heuvelink, E., Rembialkowska, E., Van Bruggen, A.H.C., 2010. Differences in $\mathrm{N}$ uptake and fruit quality between organically and conventionally grown greenhouse tomatoes. Agron. Sust. Dev. 30, 797-806.

Hallmann, E., 2012. The influence of organic and conventional cultivation systems on the nutritional value and content of bioactive compounds in selected tomato types. J. Sci. Food Agric. 92, 2840-2848.

Hamid, A.A., Aiyelaagbe, O.O., Usman, L.A., Ameen, O.M., Lawal, A., 2010 Antioxidants: its medicinal and pharmacological applications. Afr. J. Pure Appl. Chem. 4, 142-152.

Magkos, F., Arvaniti, F., Zampelas, A., 2001. Organic food: nutritious food or food for thought? A review of the evidence. Int. J. Food Sci. Nutr. 54, 357-371.

Mitchell, A., Hong, Y., Koh, E., Barrett, D., Bryant, D., Denison, R., Kaffka, S., 2007. Ten-year comparison of the influence of organic and conventional crop management practices on the content of flavonoids in tomatoes. J. Agric. Food Chem. 55, 6154-6159.

Oliveira, A.B., Moura, C.F.H., Gomes-Filho, E., Marco, C.A., Urban, L., Miranda, M.R.A., 2013. The impact of organic farming on quality of tomatoes is associated to increased oxidative stress during fruit development. PLoS ONE 8, e56354.

Palozza, P., Parrone, N., Catalano, A., Simone, R., 2010. Tomato lycopene and inflammatory cascade: basic interactions and clinical implications. Curr. Med. Chem. 17, 2547-2563.

Pérez-Clemente, R.M., Vives, V., Zandalinas, S.I., López-Climent, M.F., Munõz, V., Gómez-Cadenas, A., 2013. Biotechnological approaches to study plant responses to stress. BioMed Res. Int. 2013, 1-10.

Petkovsek, M., Slatnar, A., Stampar, F., Veberic, R., 2010. The influence of organic/ integrated production on the content of phenolic compounds in apple leaves and fruits in four different varieties over a 2-year period. J. Sci. Food Agric. 90, $2366-2378$.

Ried, K., Fakler, P., 2011. Protective effect of lycopene on serum cholesterol and blood pressure: meta-analyses of intervention trials. Maturitas 68, 299-310.

Sanborn, M., Kerr, K.J., Sanin, L.H., Cole, D.C., Bassil, K.L., Vakil, C., 2007. Non-cancer health effects of pesticides: systematic review and implications for family doctors. Can. Fam. Physician 53, 1712-1720.

Smith-Spangler, C.S., Brandeau, M.L., Hunter, G.E., Bavinger, C.J., Pearson, M.B.S., Eschbach, P.J., Sundaram, V., Liu, H., Schirmer, P., Stave, C., Olkin, I., Bravata, D.M., 2012. Are organic foods safer or healthier than conventional alternatives? a systematic review. Ann. Intern. Med. 157, 348-366.

Stommel, J., Abbott, J., Saftner, R., Camp, M., 2005. Sensory and objective quality attributes of beta-carotene and lycopene-rich tomato fruit. J. Am. Soc. Hortic. Sci. 130, 244-251.

Tarozzi, A., Hrelia, S., Angeloni, C., Morroni, F., Biagi, P., Guardigli, M., Cantelli- Forti, G., Hrelia, P., 2006. Antioxidant effectiveness of organically and non-organically grown red oranges in cell culture systems. Eur. J. Nutr. 45, 152-158. 
Toor, R.K., Savage, G.P., 2005. Antioxidant activity in different fractions of tomatoes. Food Res. Int. 38, 487-494.

Vallverdu' -Queralt, A., Bendini, A., Tesini, F., Valli, E., Lamuela-Raventos, R., Toschi, T., 2013. Chemical and sensory analysis of commercial tomato juices present on the Italian and Spanish markets. J. Agric. Food Chem. 61, 1044-1050.

Villanueva, N.D.M., 2003. Avaliação do desempenho de quatro métodos de escalonamento em testes sensoriais de aceitação utilizando modelos normais aditivos de análise de variância e mapas internos de preferência. PhD Thesis, University of Campinas, Brazil.
Vinha, A., Alves, R., Barreira, S., Castro, A., Costa, A., Oliveira, B., 2014. Effect of peel and seed removal on the nutritional value and antioxidant activity of tomato (Lycopersicon esculentum L.) fruits. LWT - Food Sci. Technol. 55, 197-202.

Weibel, F., Bickel, R., Leuthold, S., Alfoldi, T., 2000. Are organically grown apples tastier and healthier? A comparative field study using conventional and alternative methods to measure fruit quality. Acta Hortic. 57, 417-426.

Worthington, V., 2001. Nutritional quality of organic versus conventional fruits, vegetables, and grains. J. Altern. Complement. Med. 7, 161-173. 